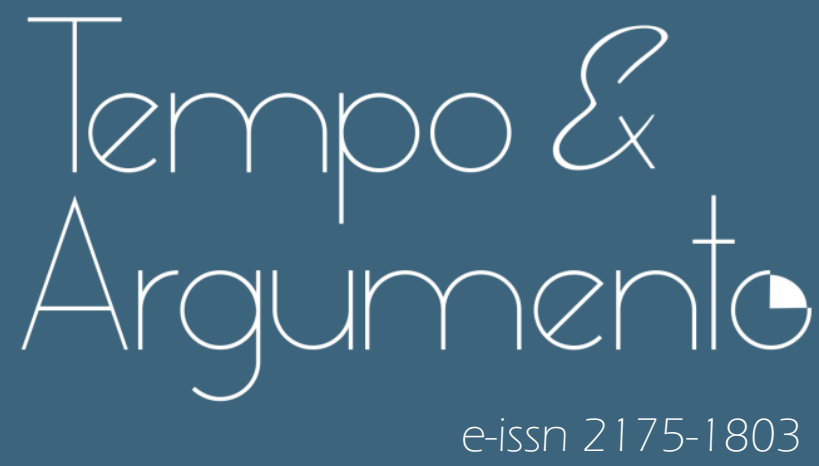

\title{
História da saúde no tempo presente: pandemias contemporâneas e o ofício dos historiadores
}

\section{Entrevista com}

* Helena da Silva

Doutora em História Contemporânea pela École des Hautes Études en Sciences Sociales e pela Universidade do Minho (UMinho). Investigadora no Instituto de História Contemporânea (IHC) da Universidade Nova de Lisboa (NOVA).

Lisboa - PORTUGAL cienciavitae.pt/pt/C213-36AB-7226

helenadasilva@fcsh.unl.pt

(i) orcid.org/0000-0002-0103-4291

Entrevista concedida ̀̀

\& Gabriela Lopes Batista

Doutoranda em História na Universidade do Estado de Santa Catarina (UDESC).

Florianópolis, SC - BRASIL

lattes.cnpq.br/4600434137653280

gabilopes04@yahoo.com.br

(D) orcid.org/0000-0003-3537-6801

* Dones Cláudio Janz Júnior

Doutorando em História na Universidade do Estado de Santa Catarina (UDESC).

Florianópolis, SC - BRASIL

lattes.cnpq.br/6240071441822344

donesjr@hotmail.com

(iD) orcid.org0000-0002-0524-5731

Para citar este texto:

SILVA, Helena da. História da saúde no tempo presente: pandemias contemporâneas e o ofício dos historiadores. [Entrevista realizada em abril de 2020]

Revista Tempo e Argumento, Florianópolis, v. 12, n. 29, e0401. jan/abr. 2020.

Entrevistadores: Gabriela Lopes Batista e Dones Cláudio Janz Júnior

dx.doi.org/10.5965/21751803122292020e040 1 


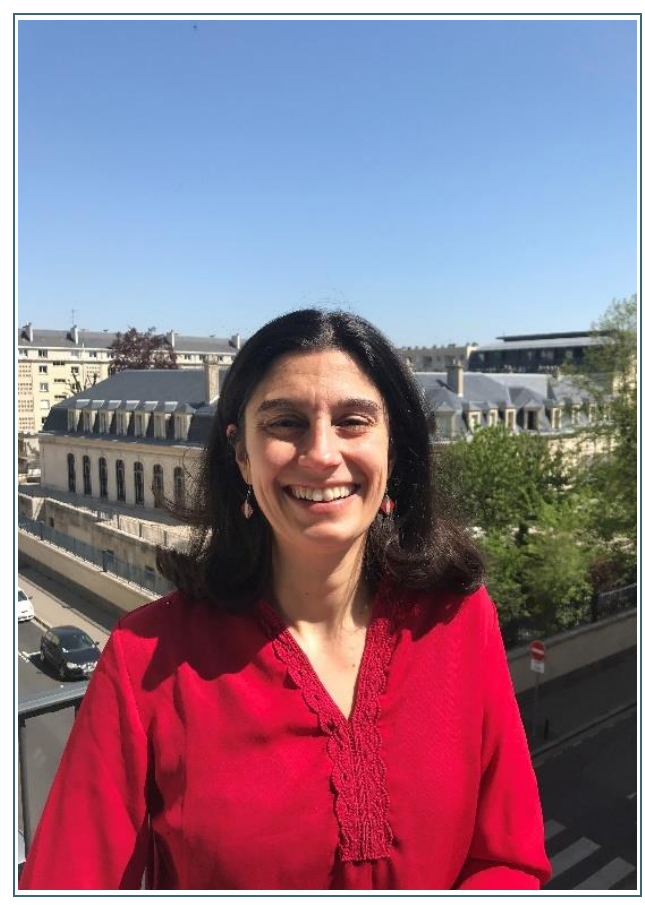

Helena da Silva é historiadora, especialista em História da Saúde. Foi investigadora FCT no Instituto de História Contemporânea da Universidade Nova de Lisboa (IHC-NOVA/FCSH) com um projeto sobre os cuidados de saúde aos soldados portugueses durante e após a Primeira Guerra Mundial (IF/00631/2014/CP1221/CT0004). Doutorada em História Contemporânea pela École des Hautes Études en Sciences Sociales e pela Universidade do Minho, é autora do livro La naissance de la profession infirmière: le cas portugais (Saint-Denis: PubliBook, 2020) e de outros trabalhos relacionados com a história da saúde, dos hospitais e da enfermagem.

Tempo \& Argumento: Qual sua trajetória de pesquisa e que caminhos a levaram para o aprofundamento nos estudos sobre História da Saúde? Além disso, poderia nos falar brevemente sobre quais são os principais interesses e temas da história da saúde em Portugal no tempo presente?

Helena da Silva: O meu interesse pelo tema da História da Saúde surgiu ainda durante a minha licenciatura em História. Nessa altura fiz um ano Erasmus na National University of Ireland Maynooth onde escolhi uma cadeira sobre História da Medicina; e aí, ao fazer várias pesquisas sobre hospitais e enfermeiras, percebi o quanto havia por explorar neste tema em Portugal.

Uns anos depois fiz então o meu doutorado num tema ligado à História da Enfermagem na École des Hautes Études en Sciences Sociales (Paris), em co-tutela com a Universidade do Minho. Por isso tenho vários trabalhos sobre a profissionalização da enfermagem e sobre

\footnotetext{
* Nesse texto optou-se por manter a grafia da língua nativa (Língua Portuguesa - Portugal).
} 
hospitais, sobretudo o Hospital de Santo António no Porto. Nos últimos cinco anos, trabalhei mais a questão da saúde e da Primeira Guerra Mundial, incluindo após o conflito. Nesse contexto trabalhei a questão da pandemia de "Gripe Espanhola", bem como a Cruz Vermelha Portuguesa ou ainda as questões do trauma pós-guerra.

Em Portugal, a História da Saúde é um tema que tem suscitado maior interesse, e atualmente é muito diversificado e pluridisciplinar. Com os colegas Ricardo Castro e Alexandra Marques criamos e temos mantido um seminário de investigação desde 2016 na Faculdade de Ciências Sociais e Humanas da Universidade Nova de Lisboa sobre a História da Saúde e da Medicina. O objetivo era convidar investigadores da área e ter assim um espaço de diálogo e de debate sobre o tema. Como este é transversal a toda a sociedade, há trabalhos sobre arquitetura hospitalar, cuidados materno-infantis, psiquiatria, institutos científicos, formação de médicos, personalidades médicas, entre muitas outras investigações em curso.

Tempo \& Argumento: A partir de suas pesquisas em temas ligados a saúde e doença, poderia nos escrever sobre os pontos de contato entre os estudos feitos no Brasil e em Portugal no que tange ao século XX?

Helena da Silva: Infelizmente, as minhas pesquisas têm poucos pontos de contato entre Brasil e Portugal. Durante o doutorado analisei mais a questão da enfermagem comparando com o caso francês e britânico, que foram influenciando Portugal. Aliás, seria possível e interessante fazer um paralelismo com o caso brasileiro. Quem sabe, se no futuro o farei!

No caso dos hospitais que trabalhei, foram poucas as referências ao Brasil. e também as pesquisas sobre a Saúde e a Grande Guerra, levaram mais a comparações com outros países aliados, e por razões óbvias, não tanto com o Brasil.

Sem dúvida que deveriam existir mais pontes na investigação entre Portugal e Brasil. Talvez para tal seja necessário aprofundar as ligações entre as nossas universidades e institutos de investigação. 
Tempo \& Argumento: Houve muitas epidemias durante a história, que se espalharam por locais diversos, mas poucas apresentaram abrangência geográfica comparável com pandemias da época contemporânea, pois hoje o contágio é bem mais célere e impetuoso. Ao comentar cenários como esse, o historiador brasileiro Cláudio Bertolli Filho assevera que "toda epidemia é acompanhada por seu duplo: a epidemia de medo". Como analisa as condições de vida de momentos pandêmicos contemporâneos distintos como a Gripe Espanhola ("Pneumônica" em Portugal) de 1918 e a Covid-19 atual?

Helena da Silva: Recentemente muitos jornalistas tentam encontrar semelhanças entre a "Gripe Espanhola" e a Covid-19. Contudo, julgo que as diferenças são muitas, sobretudo nas condições de vida da população. Quando a pandemia de "Gripe Espanhola" se propagou pelo Mundo em 1918-19, este vivia em guerra há quase 4 anos, com graves consequências económicas e sociais. No caso de Portugal, a população vivia em péssimas condições e a pobreza era uma realidade. O preço dos bens essenciais não parava de aumentar e a população tinha dificuldade em alimentar-se corretamente. A maioria da população vivia em alojamentos insalubres, sem saneamento ou água potável. E, claro, faltavam hospitais, médicos, farmácias, enfermeiros e tratamentos para fazer face ao vírus.

Hoje a situação é bem diferente. Portugal tem um Serviço Nacional de Saúde com mais de 40 anos de experiência que garante um acesso universal à saúde, bem como um sistema hospitalar bem desenvolvido e apetrechado, e ainda profissionais de saúde com formação universitária. A população sofreu bastante com a crise de 2008 mas nos últimos anos a economia melhorou, e Portugal começou 2020 em crescimento, com menos desemprego, e consequentemente uma situação positiva. Paralelamente, a população portuguesa vive hoje em condições habitacionais e laborais muito superiores às de 1918.

Claro que noutros países, a situação hoje ainda é caótica, com grandes desigualdades sociais, habitações sem água potável, populações subnutridas e sem acesso gratuito a hospitais ou cuidados de saúde. E isso terá certamente consequências diferentes no balanço da pandemia atual. Essa será uma análise comparativa a efetuar quando a pandemia de Covid-19 terminar. 
Tempo \& Argumento: No cenário que a Covid-19 nos coloca, muitos são os discursos e usos de pesquisas ligadas à história das pandemias em diversos veículos de comunicação, a fim de estabelecer paralelos e refletir sobre estratégias de prevenção ou profilaxia adotadas em diferentes contextos. Como você analisa os usos dessas pesquisas? Qual a importância e papel dos historiadores, sobretudo que trabalham com história da saúde, neste momento? Por fim, o que acha da quantidade e dispersão de fontes relacionadas ao Covid-19 e como podem ser usadas pelos historiadores?

Helena da Silva: A História não se repete, contudo podemos aprender com o passado para melhor compreender e agir no presente. Por isso, julgo que é importante e mesmo essencial o uso de pesquisas ligadas à história das pandemias, sobretudo para a população em geral perceber que a situação atual que se vive não é totalmente nova e que já houve outras pandemias, outras quarentenas, outras crises sanitárias. Se essas pesquisas forem utilizadas corretamente, com cautela e fazendo comparações com o presente, o seu uso pode ser positivo e podem servir para serenar ou acalmar a população. Podem, por exemplo, ajudar a mostrar como no passado também houve doenças que o Homem desconhecia, como foi então feito o combate e quais os resultados.

Claro que, de repente, os historiadores surgem como uma necessidade e a história da saúde como algo fundamental na sociedade, com impactos económicos e políticos. E tenho a sensação que algumas pessoas descobriram que havia historiadores da saúde e que as pesquisas destes são importantes e revelantes. Este é por isso um momento crucial para os historiadores, em particular da saúde, que devem dar a conhecer os seus estudos e investigações, sobretudo para a população em geral, e assim responder ao critério de divulgação e vulgarização da investigação que nos é constantemente exigido. É também a oportunidade de provar o interesse pela disciplina na sociedade, que a História não é apenas o passado mas está sempre relacionada com o presente.

Quanto à questão das fontes, a dificuldade em pesquisar a pandemia de "Gripe Espanhola" deveu-se em parte à falta de fontes, pelo menos no caso português, onde faltaram imagens e relatos pessoais mas também de notícias nos jornais. Hoje com a pandemia de Covid-19 o problema será o excesso de fontes. Na era digital, a quantidade de 
fotografias e vídeos que circulam nas redes sociais é imensa, entre material oficial, privado, humorístico ou ainda as "fake-news". Ou seja, há um pouco de tudo, desde imagens de locais encerrados, de cidades desertas, de hospitais de campanha, de pessoal de saúde, de como fazer uma máscara caseira, mas também de como se ocupar na quarentena, como fazer desporto em casa, ocupar as crianças, fazer pão, etc. E depois existem também todas as informações dos media, com contagens diárias e centenas de notícias relacionadas, de forma direta ou indireta, sobre a Covid-19.

De certa forma acho que os futuros investigadores que tiverem de analisar estas fontes correm o risco de ficarem perdidos no meio de tanta coisa. Terão certamente de escolher apenas uma parte e focarem-se num tema: como os media reagiram, como a população reagiu, como os profissionais de saúde reagiram, como a economia reagiu, entre muitas possibilidades. Convém referir que têm surgido plataformas online para recolher materiais sobre a pandemia atual para utilização futura, como o Coronarchiv ${ }^{1}$ na Alemanha, na Universidade de Cambridge ${ }^{2}$ ou no Heinz History Center ${ }^{3}$ apenas para referir três exemplos mas existem outros e certamente que haverá novos projetos.

Tempo \& Argumento: Comparando as falas dos governos em 1918 - pandemia de Espanhola - e 2009 - pandemia de H1N1 - o historiador brasileiro Cláudio Bertolli Filho aponta semelhanças surpreendentes nos discursos oficiais, as quais incluem: "essas epidemias são problemas de outros, europeus ou norte-americanos"; "se chegasse aqui a epidemia, haveria assistência médica e medicamentos para todos, acrescentando-se ainda que a gripe não era muito diferente de uma gripe comum". Na atualidade, no Brasil, o presidente comparou o Covid-19 a uma gripe comum, tendo depois que se retratar. Como a senhora lê essas semelhanças e quais impactos decorrem da negação da gravidade das epidemias feita pelos governos, como no caso brasileiro?

\footnotetext{
${ }^{1}$ https://coronarchiv.geschichte.uni-hamburg.de/projector/s/coronarchiv/page/willkommen

2 https://www.cam.ac.uk/stories/CollectingCovid-19

${ }^{3}$ https://www.heinzhistorycenter.org/collections/collecting-materials-related-to-thecoronavirus-covid-19-response
} 
Helena da Silva: É comum a ideia que as epidemias são problemas de outros e que vêm do exterior. Foi o caso da sífilis, onde um novo país afetado dava-lhe o nome do seu vizinho. Assim, em França foi chamado do mal de Nápoles, em Itália, na Alemanhã e Inglaterra era o mal-francês, para os Russos o mal-polonês, para os Polacos o mal-alemão, apenas para dar alguns exemplos.

Por outro lado, a negação da epidemia é também algo comum. Aliás, em 1992, Charles Rosenberg descreveu que as epidemias tinham uma espécie de ciclo onde a primeira etapa era a negação e revelação progressiva com uma certa incerteza, seguindo-se uma fase de aceitação e de procura de justificações para depois se entrar no reconhecimento da epidemia e na tomada de medidas face à crise coletiva, terminando muitas vezes de forma brusca e levando ao esquecimento da epidemia.

Podemos dizer que inicialmente a Covid-19 foi negada e minorizada, incluindo na Europa, nos Estados Unidos e no Brasil. Primeiro, era um vírus que afetava a China e a Ásia, como se ele conhecesse fronteiras. Depois o vírus foi visto como uma gripe banal, que aliás causava uma menor mortalidade do que a gripe, logo sem motivo para preocupação. Em Portugal, todos os anos a gripe mata muitas pessoas mesmo se essa não é uma das doenças mais temidas pela população em comparação com o câncer, por exemplo. A situação em Itália e em Espanha piorou muito rápido, o que levou a uma alteração do discurso; no caso português foi então dada prioridade ao controlo da pandemia através da quarentena e do isolamento da população, tentando reduzir o número de casos e evitar o colapso do sistema de saúde, apesar das consequências económicas e sociais da quarentena.

Face a esta pandemia que se propaga muito rapidamente e com muitos indivíduos assintomáticos, alguns países demoraram mais tempo a reagir. Mesmo se essa reação foi de uma ou duas semanas, esses países arriscam-se a ter um balanço final muito mais pesado, com um número de mortes muito superior. Claro que outros fatores podem interferir, como o acesso aos cuidados de saúde através de um sistema gratuito e universal, a questão das desigualdades sociais, a própria tipologia da população (jovem, saudável), entre outros.

O Brasil, como todo o continente americano, já podia ter tirado o exemplo do que estava a acontecer na Europa e na Ásia, reagindo e atuando rapidamente. Contudo, no caso do presidente brasileiro, ele 
parece ter ficado petrificado entre a fase da negação e da aceitação, não querendo adoptar as medidas aconselhadas pelo então Ministro da Saúde, Henrique Mandetta, pondo em risco a saúde da população. Veremos qual será o resultado mas para já podemos lamentar que não tenham sido tomadas medidas mais cedo, que poderiam beneficiar todo o Mundo.

Tempo \& Argumento: No tempo presente, são muitas as estratégias novas de combate à pandemia como o uso de programas de celulares para geolocalização dos contaminados feitos na Coréia do Sul, mas elas coexistem com estratégias 'arcaicas' de enfrentamento de doenças infecciosas - os antiquíssimos cordões sanitários, como o praticado em Hubei, na China, e as quarentenas aplicadas pelo mundo. Diante disso, quais os aprendizados possíveis com essas experiências? Como esse contexto pode nos servir de legado?

Helena da Silva: Sabemos que as quarentenas são medidas de baixa efetividade científica e com consequências nefastas para as populações, muitas vezes motivadas por outros motivos como questões políticas ou económicas. Conscientes das consequências, os países têm aplicado as quarentenas e até cordões sanitários (por exemplo em Ovar, Portugal), colocando milhões de pessoas em isolamento domiciliário e não apenas um grupo restrito. Neste caso, a quarentena pretende evitar o colapso dos sistemas de saúde, reduzindo o número de novos infetados e retardando a propagação do vírus.

Face a um vírus letal e invisível, legitimaram-se práticas de quarentena e de exclusão social. O receio e o pânico levaram a população a aceitar de forma quase unânime as restrições impostas, perdendo direitos básicos como a liberdade individual de movimento. A pandemia deu assim aos Estados plenos direitos e estes têm utilizado como nunca o seu poder para subjugar e controlar a população, mesmo em regimes democráticos. Veja-se o caso de Portugal onde o Estado de Emergência foi adoptado pela primeira vez em 45 anos de democracia. Assim, os Estados dotaram-se de instrumentos jurídicos para enfrentar com mais poder a pandemia para proteger vidas, num claro exercício de biopoder como definido por Foucault.

Mas além da 'arquaica' quarentena, com as novas tecnologias surgiram novas formas de vigiar constantemente os indivíduos, numa larga 
escala. Por exemplo, o uso de programas de celulares para geolocalização dos contaminados como na Coreia do Sul ou o recurso a drones até em Portugal. Os programas de geolocalização estão a ser desenvolvidos para utilização em vários países europeus, como em França, com uma explícita autorização do indivíduo, que assim aceita ser constantemente vigiado. Há aqui um claro risco de abuso deste controlo, tal como de perder permanentemente algumas liberdades individuais. Mas certamente que o exercício deste controlo e desta vigilância será restrito ao período da pandemia.

Perante isto tenho mais questões do que respostas sobre o que podemos aprender desta pandemia. Recorde-se que a OMS tinha feito avisos de que uma nova pandemia de gripe ou de uma doença $X$ estaria iminente, mas poucos levaram estes avisos a sério e se prepararam. Assim, questiono-me se no futuro esta pandemia será também esquecida, como outras no passado, ou se realmente se aprenderá algo com todas estas novas estratégias de combate ao vírus. Para as futuras epidemias ou pandemias continuaremos a utilizar as quarentenas de forma generalizada à população? Ou passaremos a utilizar em larga escala uma vigilância tecnológica para controlar as doenças?

Mas sobretudo, seremos realmente capazes de retirar lições da situação atual, da resposta ou não-resposta dos Estados? Trará esta pandemia alterações estruturais na sociedade? Teremos no futuro uma sociedade centrada no capital saúde e uma política em favor dos sistemas de saúde públicos? Iremos repensar o nosso modo de vida, as nossas relações humanas, as nossas liberdades, as nossas cidades? Será posta em causa a sociedade consumista e globalizada?

Universidade do Estado de Santa Catarina - UDESC

Programa de Pós-Graduação em História - PPGH Revista Tempo e Argumento Volume 12 - Número 29 - Ano 2020 tempoeargumento@gmail.com 